\title{
P02-005 - Overlap of FMF and HIDS in one Arabic family
}

\author{
T Moussa $^{1 *}$, B Aladbe ${ }^{2}$, A Aly ${ }^{1}$, R Taha ${ }^{3}$, H El-Shanti ${ }^{3}$, B Fathalla ${ }^{2}$ \\ From 7th Congress of International Society of Systemic Auto-Inflammatory Diseases (ISSAID) \\ Lausanne, Switerland. 22-26 May 2013
}

\section{Introduction}

Familial Mediterranean Fever (FMF) is commonly reported in Arabs, whereas Hyper-IgD syndrome (HIDS) is rare. Moreover, the simultaneous presence of $M E F V$ and $M V K$ mutations segregating in the same family is exceedingly rare. We report here an Arabic family in whom a combination of complex $M E F V$ mutations and an $M V K$ mutation segregate producing variable clinical phenotypes.

\section{Case report}

An 8-year-old female presented with episodes of fever, abdominal pain, vomiting, and arthralgia lasting 3-5 days for 1-year duration suggestive of FMF. Atypical FMF features included longer episodes of fever and partial response to colchicine. Family history revealed HIDS in an 18 years old brother. He presented with episodes of fever, abdominal pain, vomiting, diarrhea, skin rash, lymphadenopathy, and febrile seizures since 1 year of age and was treated as clinical FMF with colchicine for 4 years with poor response. Genetic testing for HIDS done at 7 years of age showed homozygosity of V377I mutation. He was not responsive to Statins but became asymptomatic after puberty. At 17 years of age he developed short episodes of fever and abdominal pain more consistent with FMF. He was responsive to bursts of prednisone during episodes but not compliant with colchicine due to severe diarrhea.

Genetic testing was done for both patients and asymptomatic family members by sequence analysis of entire MEFV and MVK as well as TNFRSF1A, PSTPIP1, IL1RN and LPIN2 coding regions and splice sites. Asymptomatic parents are carriers of V377I/- $M V K$ mutation. The father is a compound heterozygote for two complex MEFV mutations, E148Q/P369S/R408Q and E167D/

${ }^{1}$ Pediatrics, Hamad General Hospital, Doha, Qatar

Full list of author information is available at the end of the article
F479L whereas the mother is a compound heterozygote for M680I and the complex allele E148Q/P369S/R408Q. Both of our patients are homozygous for V377I $M V K$ mutation, the girl is compound heterozygote for E148Q/ P369S/R408Q and E167D/F479L MEFV mutations whereas the boy is compound heterozygote for E148Q/ P369S/R408Q and M680I.

\section{Discussion}

The presence of concomitant mutations in different genes of monogenic autoinflammatory diseases (AID) could act as potential disease modifiers. Clinical implications to such combinations are not clear but may explain overlap or atypical clinical features. Such combinations have been scarcely reported including TNFRS1A and MEFV mutations, MVK and TNFRSFA1 mutations, and CIAS1 and MEFV mutations. Utilizing the diagnostic score and proposed diagnostic algorithm for molecular analysis of hereditary AID with periodic fever in children could have possibly resulted in genetic testing for one AID and missed such combinations. Our reported family does suggest that multiple mutations/ variants in AID genes can occur in the same patient and could potentially influence the clinical presentation and response to treatment.

\section{Disclosure of interest}

None declared.

\section{Authors' details \\ ${ }^{1}$ Pediatrics, Hamad General Hospital, Doha, Qatar. ${ }^{2}$ Pediatrics/Rheumatology, Hamad General Hospital, Doha, Qatar. ${ }^{3}$ Medical Genetics, Shafallah Medical Genetics Center, Doha, Qatar. \\ Published: 8 November 2013 \\ References \\ 1. El-Shanti $\mathrm{H}$, et al: Familial Mediterranean fever in Arabs. Lancet 2006 367:1016-1024.}


2. Granel B, et al: Overlap syndrome between FMF and TRAPS in a patient carrying MEFV and TNFRSF1A mutations. Clin Exp Rheumatol 2007, 25(4 Suppl 45):S93-5.

3. Van der Hilst JC, et al: International HIDS Study Group. Long-term followup, clinical features and quality of life in a series of 103 patients with hyperimmunoglobulinemia D syndrome. Medicine (Baltimore) 2008, 87:301-310.

doi:10.1186/1546-0096-11-S1-A112

Cite this article as: Moussa et al.: P02-005 - Overlap of FMF and HIDS in one Arabic family. Pediatric Rheumatology 2013 11(Suppl 1):A112.

Submit your next manuscript to BioMed Central and take full advantage of:

- Convenient online submission

- Thorough peer review

- No space constraints or color figure charges

- Immediate publication on acceptance

- Inclusion in PubMed, CAS, Scopus and Google Scholar

- Research which is freely available for redistribution

Submit your manuscript at www.biomedcentral.com/submit
C Biomed Central 